\title{
Increase of PD-L1 expressing B-precursor ALL cells in a patient resistant to the CD19/CD3-bispecific T cell engager antibody blinatumomab
}

Thomas Köhnke ${ }^{1,2}$, Christina Krupka ${ }^{1,2}$, Johanna Tischer ${ }^{1}$, Thomas Knösel ${ }^{3}$ and Marion Subklewe ${ }^{1,2^{*}}$

\begin{abstract}
The bispecific T cell engager blinatumomab has shown encouraging clinical activity in B-precursor acute lymphoblastic leukemia (ALL). However, about half of relapsed/refractory patients do not respond to therapy. Here, we present the case of a 32-year-old male patient with refractory B-precursor ALL who was resistant to treatment with blinatumomab. Bone marrow immunohistochemistry revealed T cell infiltrates and an increase in programmed death-ligand 1 (PD-L1)positive ALL cells as a potential immune escape mechanism. We were able to recapitulate the clinical observation in vitro by showing that blinatumomab was not able to mediate cytotoxicity of CD19-positive ALL cells using autologous T cells. In contrast, the addition of healthy donor T cells led to lysis of ALL cells.

These results strongly encourage further systematic evaluation of checkpoint molecules in cases of blinatumomab treatment failure and might highlight a possible mechanism to overcome resistance to this otherwise highly effective treatment.
\end{abstract}

Keywords: ALL, Immunotherapy, Blinatumomab, Immune checkpoints, T cells, Combination therapy

\section{Background}

Bispecific $\mathrm{T}$ cell engaging $\left(\mathrm{BiTE}^{\circ}\right)$ antibody constructs represent a novel class of therapeutic antibodies, which are comprised of two single-chain variable fragments simultaneously binding CD3-positive T cells and a specific tumor target antigen [1]. Blinatumomab is the first of $\mathrm{BiTE}^{\bullet}$ antibody construct which entered the clinic and simultaneously binds CD3-positive $\mathrm{T}$ cells and CD19positive $\mathrm{B}$ cells. The design of this BiTE ${ }^{\bullet}$ molecule brings CD19-positive target cells in close contact with CD3positive $\mathrm{T}$ cells. Importantly, binding of the $\mathrm{BiTE}^{\circ}$ molecule results in polyclonal $\mathrm{T}$ cell activation and expansion which results in effective lysis of the target cells irrespective of $\mathrm{T}$ cell specificity $[2,3]$. Blinatumomab has shown to have antileukemic activity in patients with Bprecursor acute lymphoblastic leukemia (ALL) [4], and

\footnotetext{
* Correspondence: marion.subklewe@med.uni-muenchen.de

'Department of Internal Medicine III, Ludwig-Maximilians-Universität (LMU),

Munich, Germany

${ }^{2}$ Clinical Cooperation Group Immunotherapy at the Helmholtz Zentrum

München, Munich, Germany

Full list of author information is available at the end of the article
}

recently, blinatumomab was approved for the treatment of relapsed or refractory B-precursor ALL by the FDA (http://www.fda.gov/drugs/informationondrugs/approveddrugs/ucm425597.htm). Loss of CD19 and extramedullary relapse have been observed as mechanisms of resistance to blinatumomab treatment $[5,6]$; however, other mechanisms of resistance have not been reported so far.

Upregulation of programmed death-ligand 1 (PD-L1) on tumor cells in response to endogenous anti-tumor immunity [7] inhibits adaptive immune responses by inducing $\mathrm{T}$ cell dysfunction [8]. Expression of PD-L1 on tumor cells has been associated with poor outcome in solid cancers [9] as well as hematologic malignancies [10]. Antibodies targeting PD-L1 as well as its receptor on $\mathrm{T}$ cells, programmed cell death-1 (PD-1), are being evaluated in a variety of cancers $[9,11,12]$, including lymphoid malignancies [7]. Recently, two antibodies targeting PD-1 were granted approval for the treatment of advanced melanoma (pembrolizumab, nivolumab) as well as metastatic squamous non-small cell lung cancer (nivolumab). Interestingly, activity of these therapies is 
not limited to PD-L1-positive cancers, as clinical responses could be detected in cases with low PD-L1 expression [13]. There is extensive research in the field trying to develop improved predictive biomarkers to identify those patients which will response to mono- as well as combination immunotherapies [14].

\section{Case presentation}

A 32-year-old male patient presented with refractory Bprecursor ALL after frontline treatment with induction I and II as well as consolidation I of the German multicenter study group on adult acute lymphoblastic leukemia (GMALL) treatment protocol (analogous to the GMALL trial 07/2003, Clinicaltrials.gov identifier: 00198991). He was subsequently transferred to our center and received blinatumomab as a continuous infusion at a dose of $9 \mu \mathrm{g} /$ day for 7 days and $28 \mu \mathrm{g} /$ day for the subsequent 21 days. Bone marrow blast count prior to treatment with blinatumomab (baseline) was $30 \%$ (Fig. 1c, left panel), and lymphoblasts homogenously
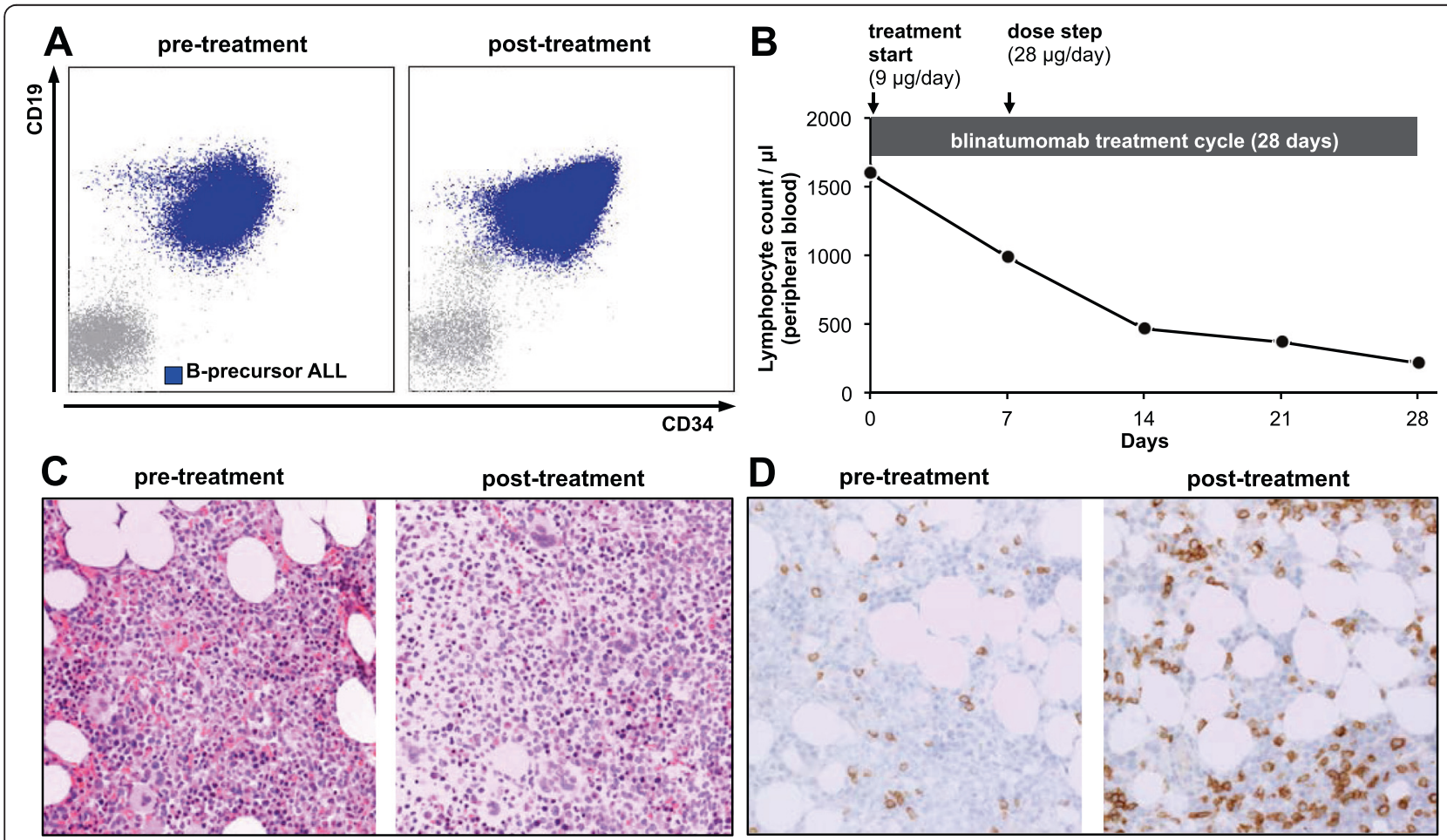

D

pre-treatment

post-treatment
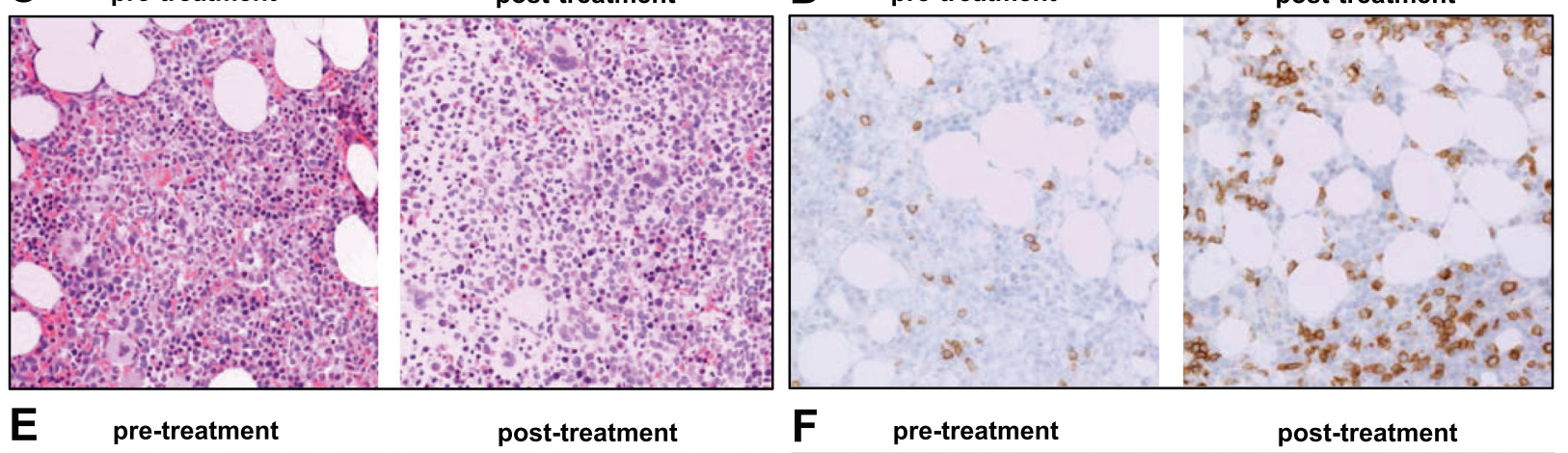

post-treatment

$\mathbf{F}$

F pre-treatment

post-treatment
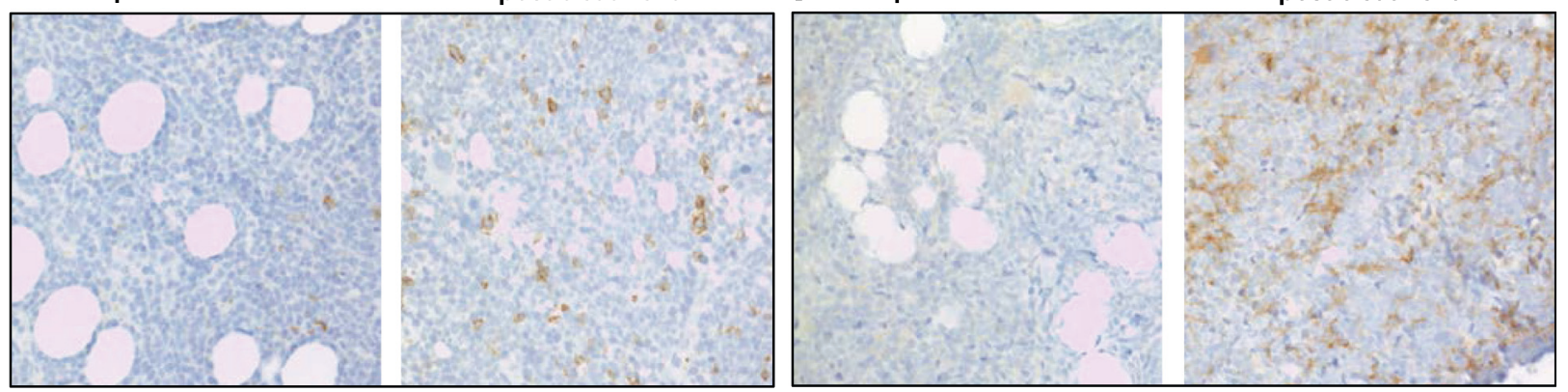

Fig. 1 Increase of PD-1 and PD-L1 positivity after treatment with blinatumomab. a CD19 vs. CD34 expression of lymphoblasts detected by flow cytometry. Lymphoblasts showed homogenous expression of CD19 at baseline (pre-treatment) as well as after blinatumomab treatment (post-treatment). b Lymphocyte counts on peripheral blood during blinatumomab treatment. Lymphocyte counts decreased during blinatumomab treatment (1596/ $\mu$ on day $0,986 / \mu$ l on day $7,464 / \mu$ l on day $14,368 / \mu$ l on day 21 , and $217 / \mu$ l on day 28 ). c Hematoxylin and eosin stain of paraffin embedded bone marrow core biopsy showing diffuse infiltration of immature progenitors at both time points (pre-treatment blast count $30 \%$, post-treatment $60 \%$ ). d Immunohistochemistry of paraffin embedded bone marrow core biopsy stained for CD3 showing spotted infiltration of CD3-positive T cells at baseline (5-10\%, pre-treatment) and diffuse infiltration after blinatumomab treatment (20-30\%, post-treatment). e Immunohistochemistry of paraffin embedded bone marrow core biopsy stained for PD-1 showing $5 \%$ PD-1-positive cells at baseline (pre-treatment) vs. $15 \%$ after blinatumomab treatment (post-treatment). $\mathbf{I} I$ mmunohistochemistry of paraffin embedded bone marrow core biopsy stained for PD-L 1 showing $2 \%$ PD-L1-positive blasts at baseline (pre-treatment) vs. $40 \%$ after blinatumomab treatment (post-treatment) 
expressed CD19 (Fig. 1a, left panel). Treatment was well tolerated with pyrexia on days 1 through 4 of blinatumomab treatment being the only adverse event. Examination of peripheral blood revealed a decrease of total lymphocyte counts during treatment $(1596 / \mu \mathrm{l}$ on day $0 \mathrm{vs.}$ $217 / \mu \mathrm{l}$ on day 28, Fig. $1 \mathrm{~b})$ including decreased T cells (960 CD3-positive $\mathrm{T}$ cells $/ \mu \mathrm{l}$ on day 5 vs. $180 / \mu \mathrm{l}$ on day 28 ). Interestingly, there was a moderate increase in CD3positive $\mathrm{T}$ cells within the bone marrow $(5-10 \%$ at baseline vs. 20-30 \% after blinatumomab treatment, Fig. 1d).

Upon completion of the first cycle, bone marrow examination revealed persistent leukemia with a blast count of $60 \%$ (Fig. 1c, right panel), showing homogenous expression of CD19 (Fig. 1a, right panel). Since a loss of CD19 as the mechanism of resistance could not be detected, we examined PD-1 and PD-L1 expression in the bone marrow by immunohistochemistry. A moderate increase in PD-1 positivity was seen in lymphocytes in the bone marrow by immunohistochemistry (5\% PD-1-positive cells at baseline vs. $15 \%$ after blinatumomab treatment, Fig. 1e). However, we observed a marked increase of PD-L1 positivity (2\% PD-L1positive blasts at baseline vs. $40 \%$ after blinatumomab treatment, Fig. 1f). In contrast to the bone marrow, no $\mathrm{PD}-1$ expression was observed on $\mathrm{T}$ cells from the peripheral blood (Fig. 2a).

Finally, we collected the patient's peripheral blood after blinatumomab treatment and purified CD3-positive T cells (EasySep $^{\text {Tw }}$ Human CD3 Positive Selection Kit II, Stemcell
Technologies, Vancouver, British Columbia, Canada). Of either patient or healthy donor CD3-positive T cells, $2.5 \times 10^{5}$ were cocultured with $5 \times 10^{5}$ of the patient's ALL cells (CD3-negative cells) with blinatumomab or control-BiTE at a dose of $5 \mathrm{ng} / \mathrm{ml}$ on $3 \times 10^{4}$ irradiated MS- 5 feeder cells. After 3 days, cells were stained with CD19-PE, CD2BV421, and murine CD29-APC-Cy7 (all BioLegend, San Diego, CA, USA), as well as LIVE/DEAD ${ }^{\circ}$ Fixable Aqua Dead Cell Stain Kit (Life Technologies, Carlsbad, CA, USA), and analyzed on a LSR II flow cytometer (BD Biosciences, Heidelberg, Germany). After cell counting, the percentage of the respective cell population determined by flow cytometry was used to determine the absolute cell counts. Percentage of specific lysis was calculated using cell counts of control-BiTE ${ }^{\circ}$ antibody-treated relative to blinatumomab-treated cultures, as described previously [15]. The interferon- $\gamma$ (IFN- $\gamma$ ) concentration in cell culture supernatants was measured by cytometric bead array $\left(\mathrm{BD}^{\mathrm{in}}\right.$ CBA Human IFN- $\gamma$ Flex Set, BD Biosciences, Heidelberg, Germany) according to the manufacturer's instructions on the same machine.

In vitro, the patient's $\mathrm{T}$ cells showed considerably less lysis of CD19-positive cells (8.5 vs. $93.6 \%$ for healthy donor T cells, Fig. 2b, c). This was accompanied by considerably lower concentrations of IFN- $\gamma$ in cell culture supernatants ( 47.7 vs. $2100.9 \mathrm{pg} / \mathrm{ml}$ for healthy donor T cells, Fig. 2d). These results recapitulate the clinical experience with an inability of the patients' $\mathrm{T}$ cells to perform blinatumomab-mediated lysis of ALL cells.

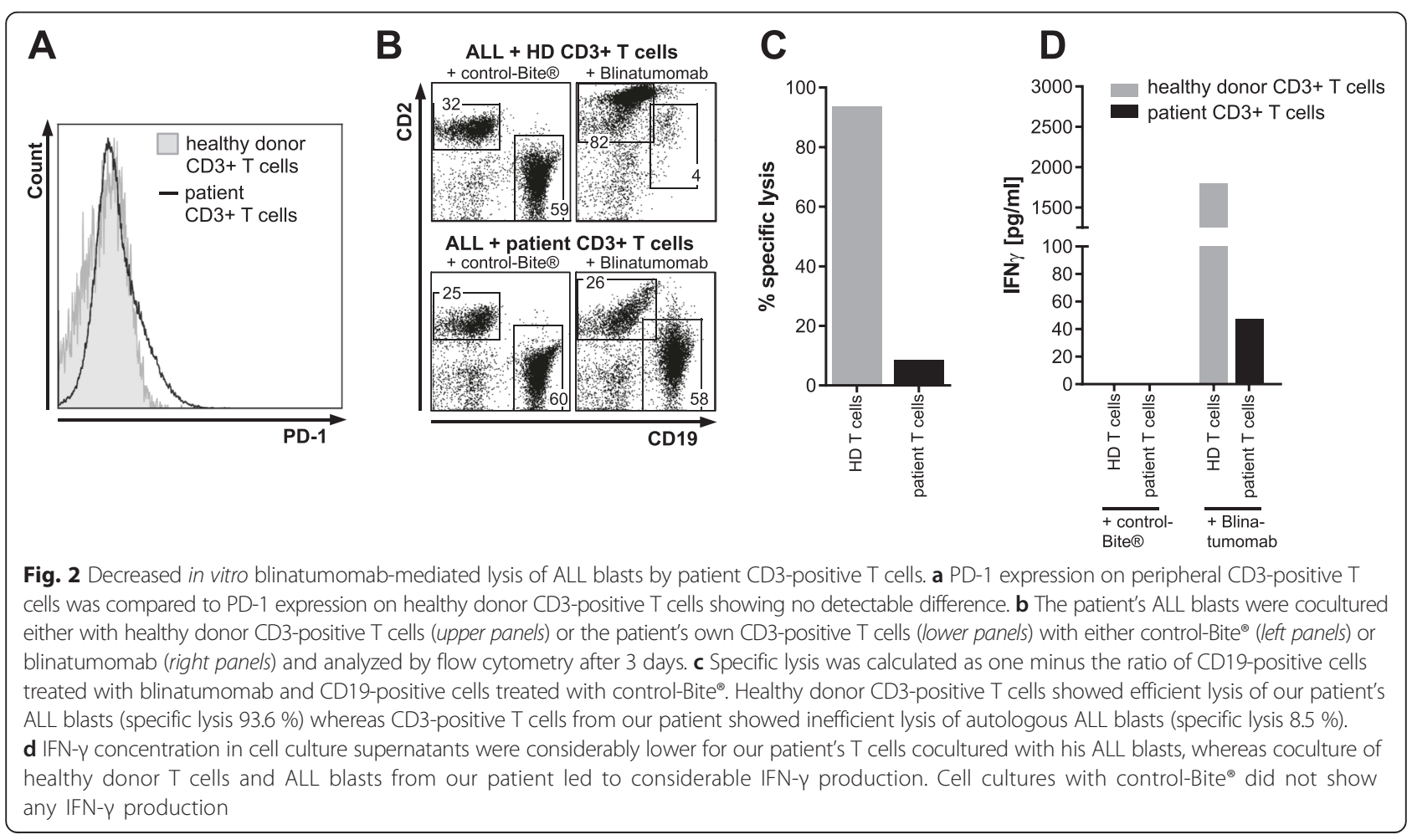




\section{Discussion and conclusions}

Taken together, our data suggests a role of PD-L1 in treatment resistance to blinatumomab in our patient. This is, to our knowledge, the first report of increased PD-L1 positivity in a patient receiving blinatumomab and should encourage a systematic evaluation of the relevance of this resistance mechanism in patients receiving bispecific $\mathrm{T}$ cell engager therapy. A large body of evidence has been suggesting a key role of the PD-1/PDL1 axis in attenuating anti-tumor immune responses $[16,17]$. Recently, we described this mechanism of resistance in the context of $\mathrm{BiTE}^{\oplus}$ antibody immunotherapy in vitro [18]. Detecting an increase of PD-L1 in a patient receiving blinatumomab therefore highlights the relevance of this mechanism in vivo.

Additionally, several resistance mechanisms to antibodybased immunotherapy have been reported including variation of target antigen expression (which might be present initially or develop during therapy), activation of alternative signaling pathways, and anti-antibody formation [19-22]. In the context of novel immunotherapies, including blinatumomab, assessment of resistance mechanisms is limited and warrants further investigation. Upregulation of checkpoint molecules represents an adaptive resistance to antitumor immunity which we hypothesize will also take place in other $\mathrm{T}$ cell recruiting antibody formats (e.g., DARTS, diabodies) as well as adoptive $\mathrm{T}$ cell therapies (e.g., CAR T cells, tumor antigen-specific TCR T cells). It will be important to conduct close monitoring of biomarkers and careful consideration of specific time points recognizing the dynamic interplay of receptor-ligand interactions. Further studies are warranted to analyze the significance of the PD1/PD-L1 interplay as a resistance mechanism to blinatumomab. Ultimately, combinatorial approaches might have the potential to revert $\mathrm{T}$ cell-induced immune escape strategies and avoid treatment failure in these otherwise highly effective treatments.

\section{Statement of informed consent}

Written informed consent was obtained from the patient for publication of this manuscript. A copy of the written consent is available for review by the Editor-in-Chief of this journal.

\begin{abstract}
Abbreviations
ALL: acute lymphoblastic leukemia; CAR T cells: chimeric antigen receptor T cells; DARTs: dual affinity re-targeting molecules; GMALL: German multicenter study group on adult acute lymphoblastic leukemia; IFN- $\gamma$ : interferon- $\gamma$; PD-1: programmed cell death-1; PD-L1: programmed death-ligand 1; TCR: T cell receptor.
\end{abstract}

\section{Competing interests}

The authors declare that they have no competing interests.

\section{Authors' contributions}

TKöhnke treated the patient, collected the material, designed the research, interpreted the data, and wrote the manuscript. CK performed the in vitro experiments. JT treated the patient. TKnösel performed the IHC stains and the histopathological evaluations. MS designed the research, interpreted the data, and supervised the project. All authors read and approved the final manuscript.

\section{Author details}

${ }^{1}$ Department of Internal Medicine III, Ludwig-Maximilians-Universität (LMU), Munich, Germany. ${ }^{2}$ Clinical Cooperation Group Immunotherapy at the Helmholtz Zentrum München, Munich, Germany. ${ }^{3}$ Institute of Pathology, Ludwig-Maximilians-Universität (LMU), Munich, Germany.

Received: 12 August 2015 Accepted: 28 September 2015

Published online: 08 October 2015

\section{References}

1. Suresh T, Lee LX, Joshi J, Barta SK. New antibody approaches to lymphoma therapy. J Hematol Oncol. 2014;7(1):58.

2. Wu J, Fu J, Zhang M, Liu D. Blinatumomab: a bispecific T cell engager (BiTE) antibody against CD19/CD3 for refractory acute lymphoid leukemia. J Hematol Oncol. 2015;8(1):104

3. Zugmaier G, Klinger M, Schmidt M, Subklewe M. Clinical overview of anti-CD19 $\mathrm{BiTE}\left({ }^{\oplus}\right)$ and ex vivo data from anti-CD33 BiTE $\left({ }^{\oplus}\right)$ as examples for retargeting $\mathrm{T}$ cells in hematologic malignancies. Mol Immunol. 2015;67(2 Pt A):58-66.

4. Topp MS, Gökbuget N, Stein AS, Zugmaier G, O'Brien S, Bargou RC, et al. Safety and activity of blinatumomab for adult patients with relapsed or refractory B-precursor acute lymphoblastic leukaemia: a multicentre, singlearm, phase 2 study. Lancet Oncol. 2014;16(1):57-66.

5. Portell CA, Wenzell CM, Advani AS. Clinical and pharmacologic aspects of blinatumomab in the treatment of B-cell acute lymphoblastic leukemia. Clin Pharmacol. 2013;5 Suppl 1:5-11.

6. Bassan R. Toward victory in adult ALL: blinatumomab joins in. Blood. 2012;120(26):5094-5.

7. Eyre TA, Collins GP. Immune checkpoint inhibition in lymphoid disease. $\mathrm{Br} J$ Haematol. 2015;170(3):291-304.

8. Shi L, Chen S, Yang L, Li Y. The role of PD-1 and PD-L1 in T-cell immune suppression in patients with hematological malignancies. J Hematol Oncol. 2013;6(1):74.

9. Ohaegbulam KC, Assal A, Lazar-Molnar E, Yao Y, Zang X. Human cancer immunotherapy with antibodies to the PD-1 and PD-L1 pathway. Trends Mol Med. 2015;21(1):24-33.

10. Homet Moreno B, Ribas A. Anti-programmed cell death protein-1/ligand-1 therapy in different cancers. Br J Cancer. 2015;112(9):1421-7.

11. Ramsay AG. Immune checkpoint blockade immunotherapy to activate anti-tumour T-cell immunity. Br J Haematol. 2013;162(3):313-25.

12. Brahmer JR, Tykodi SS, Chow LQM, Hwu W-J, Topalian SL, Hwu P, et al. Safety and activity of anti-PD-L1 antibody in patients with advanced cancer. N Engl J Med. 2012;366(26):2455-65.

13. Kefford R, Ribas A, Hamid O, Robert C, Daud A, Wolchok JD, et al. Clinical efficacy and correlation with tumor PD-L1 expression in patients (pts) with melanoma (MEL) treated with the anti-PD-1 monoclonal antibody MK-3475. ASCO Meet Abstr. 2014;32(15_suppl):3005. May 20.

14. Smith AD, Roda D, Yap TA. Strategies for modern biomarker and drug development in oncology. J Hematol Oncol. 2014;7(1):70.

15. Krupka C, Kufer P, Kischel R, Zugmaier G, Bogeholz J, Köhnke T, et al. CD33 target validation and sustained depletion of AML blasts in long-term cultures by the bispecific T-cell-engaging antibody AMG 330. Blood. 2014;123(3):356-65.

16. Madorsky Rowdo FP, Baron A, Urrutia M, Mordoh J. Immunotherapy in cancer: a combat between tumors and the immune system; you win some, you lose some. Front Immunol. 2015;26:6.

17. Taube JM, Anders RA, Young GD, Xu H, Sharma R, McMiller TL, et al. Colocalization of inflammatory response with $\mathrm{B} 7-\mathrm{H} 1$ expression in human melanocytic lesions supports an adaptive resistance mechanism of immune escape. Sci Transl Med Am Assoc Adv Sci. 2012:4(127):127ra37-7.

18. Krupka C, Kufer P, Kischel R, Zugmaier G, Lichtenegger FS, Köhnke T, et al. Blockade of the PD-1/PD-L1 axis augments lysis of AML cells by the CD33/CD3-BiTE ${ }^{\circledR}$ antibody construct AMG 330: reversing a T-cell induced immune escape mechanism. Leukemia: Nature Publishing Group; 2015. 
19. Press OW, Leonard JP, Coiffier B, Levy R, Timmerman J. Immunotherapy of non-Hodgkin's lymphomas. Hematol Am Soc. 2001;2001(1):221-40.

20. Shuptrine CW, Surana R, Weiner LM. Monoclonal antibodies for the treatment of cancer. Semin Cancer Biol. 2012;22(1):3-13.

21. Scott AM, Wolchok JD, Old LJ. Antibody therapy of cancer. Nat Publ Group. 2012;12(4):278-87.

22. Reslan L, Dalle S, Dumontet C. Understanding and circumventing resistance to anticancer monoclonal antibodies. MAbs Landes Bioscience; 2009;1(3):222-9.

\section{Submit your next manuscript to BioMed Central} and take full advantage of:

- Convenient online submission

- Thorough peer review

- No space constraints or color figure charges

- Immediate publication on acceptance

- Inclusion in PubMed, CAS, Scopus and Google Scholar

- Research which is freely available for redistribution 